\title{
Research on Pricing Strategy of Online and Offline Supply Chain Based on Channel Preference in the Context of New Retail
}

\author{
Qingtong Wu $\mathbb{1}^{1,2}$ \\ ${ }^{1}$ Macau University of Science and Technology, Macau 999078, China \\ ${ }^{2}$ Zhuhai College of Science and Technology, Zhuhai, Guangdong 519000, China \\ Correspondence should be addressed to Qingtong Wu; wuqt@jluzh.edu.cn
}

Received 28 July 2021; Accepted 16 August 2021; Published 2 September 2021

Academic Editor: Huihua Chen

Copyright (c) 2021 Qingtong Wu. This is an open access article distributed under the Creative Commons Attribution License, which permits unrestricted use, distribution, and reproduction in any medium, provided the original work is properly cited.

In recent years, brick-and-mortar retail has continuously encountered setbacks in the context of the rapid development of the Internet, and many brick-and-mortar stores cannot withstand losses and were closed down. E-commerce also seems to be able to intuitively understand the needs and preferences of consumers. With the continuous competition of online retail, the undifferentiated production of online retail has slowed down the development of e-commerce. The rise of the new retail model has promoted the production of high-quality products, which has greatly stimulated supply and demand. The new retail model is able to make better use of existing human and material resources and maximize the use of resources in today's era of rapid technological changes. Online and offline network competition channels also exert different competitive advantages for different consumers. This paper studies the competition between physical retail and e-commerce retail and combines centralized decisionmaking and decentralized decision-making for analysis. It also calculates the relative optimal pricing price of e-commerce retail through numerical simulation calculations. Although the best pricing price is obtained after a series of calculations, it is still necessary to comprehensively consider and analyze multiple factors rationally to promote the long-term development of the enterprise. Although supply chain pricing strategies can solve certain problems in market sales to a certain extent, comprehensive analysis and scientifically formulating corporate development strategies are the guarantee of sustainable business operations.

\section{Introduction}

The rapid rise of e-commerce has made the situation of the physical retail industry not optimistic, and the undifferentiated production of online retail has caused supply to exceed demand, encourage transformation through national policies, and change the traditional passive pricing strategy of market pull. The new retail model largely circumvents some shortcomings in the traditional e-commerce business process and makes more effective use of the development achievements of the logistics industry. And with the advancement of technology, many products have been updated to meet the higher demands of consumers. On the contrary, consumer purchases have also stimulated the continuous advancement of technology and promoted the development of the economy in a more prosperous direction. The new retail model will become the main mode of operation of the retail market. Hendershott and Zhang [1] studied the pricing strategy of a dual-channel supply chain between a retailer and two manufacturers and analyzed and compared the issue of profit margins and differences in the introduction of online retail channels. Balasubramanian [2] studied the pricing of a number of traditional retailers and manufacturers who introduced online sales channels and found a balanced strategy between them. Kuratan et al. [3] studied the use of price contracts to solve the problems faced in channel competition. Grewal et al. [4] built a framework based on online and offline pricing strategy management to further contribute to the research agenda. Cattani et al. [5] compared a manufacturer that has added online direct sales channels with multiple retailers to study the second-order supply chain equilibrium. Cattani [6] studied that, under the condition of constant wholesale and retail prices, the manufacturer gave the highest price and gave three supply 
chain pricing methods for reference. Boyaci [7] found through researching inventory competition that, in a dualchannel supply chain composed of a manufacturer and a traditional retailer, a single contract such as quantity discount contract, repurchase contract, and revenue-sharing contract cannot achieve supply chain coordination. Enders and Jelassi [8] constructed a dual-channel supply chain model for manufacturers to open online direct sales channels and discussed the optimal repurchase contracts in the case of information sharing and information nonsharing. Chiang [9] studied the coordination of supply chain by this improved revenue-sharing contract by adding an inventory cost sharing coefficient to the dual-channel supply chain model considering inventory competition. Chen et al. [10] studied the combination of quantity discount contract and two-part pricing contract, which can better realize dualchannel. Coordination of the supply chain will ultimately increase the profits of both manufacturers and traditional retailers. Pietro [11] domestic and foreign scholars' research on dual-channel supply chain mainly focuses on issues such as pricing decisions, service strategies, information sharing, and inventory levels. Park and Keh [12] constructed a dualchannel supply chain model for manufacturers to open direct sales channels. Among them, they separately studied the manufacturer-led and traditional retailer-led pricing models. The above methods have made large or small contributions to the research of dual-channel supply chain. This article uses existing data and pricing game theory to analyze and research the theme of supply chain through centralized and decentralized decision-making.

The documents cited in the article are all priced by retail, but with the development of economy, online economy has become a new sales method. The above literature does not consider the influence of different prices of the same goods online and offline and the influence of different pricing on the pricing of online and offline goods.

The second part of the article introduces three kinds of supply structures: online and offline. The third part puts forward the establishment of dual-channel game model and the new retail model; the fourth part evaluates the profit under the supply chain with three channel structures and obtains the influence of related variables on the price in different game models. This paper puts forward that different prices get different decision prices in the game model and finally get vertical comparison in different competitive structures: for the optimal pricing of e-commerce retail, the price under centralized decision is higher than that under decentralized decision, and the promotion effect is the most obvious.

\section{Basic Indicators of the Model}

Three types of supply structures were discovered in the consumer groups of manufacturers and retailers: singlechannel supply chain (model 0); manufacturers introduced network channels, called manufacturer dual-channel (denoted as model 0 for model 1); retailers introduced online channels, referred to as Retailer Dual Channels (referred to as model 2), which correspond to the online retail discount rate of physical retail and the degree of consumer recognition of online channels $[1,2]$.

Model 0, model 1, and model 2 proposed in this paper are single-channel supply chain, manufacturer's dualchannel, and retailer's dual-channel, respectively. Model 0 represents single-channel supply, online or offline, model 1 represents online and offline manufacturer's channel, and model 2 represents online and offline retailer's channel. They deal with different roles and are in important links of the whole supply chain.

When the sales cost of physical channels and online channels are both 0 , in a single-channel supply chain (model 0 ), the net utility of consumers buying products is $u_{0}=v_{p}$; if $u_{0}=v_{p} \geq 0$, consumers will buy this channel product. For products, if $u_{0}=v_{p}<0$, consumers will not buy products; in a dual-channel supply chain (model 1 and model 2), the net utility of consumers buying products on physical channels and online channels is $u_{i 1}=v_{p}, u_{i 2}=\delta v-n_{p}, i=1,2$ represents the dual-channel of the manufacturer (model 1$)$ and the dual-channel of the retailer (model 2). If $u_{i 1} \geq 0$ and $u_{i 1} \geq u_{i 2}$, then the consumer net utility is in the interval of $[(1-\eta / 1-\delta) p, 1]$. Consumers will purchase products through physical channels; if $u_{i 2}>0^{\prime \prime}$ and $u_{i 2}>u_{i 1}$, the consumer's net utility is in the range of $[(\eta / \delta) p$, $(1-\eta / 1-\delta) p]$, and consumers will buy products on the online channel. At the same time, in order to ensure the existence of both physical and online channels, the demands of both channels must be positive, so there are the following assumptions. Assume $60<\eta<\delta<1$.

In order to ensure the existence of dual channels, when the consumer's valuation is 1 , it is set that consumers must purchase the product through physical channels; when the consumer's valuation is $(\eta / \delta) p$, it is assumed that consumers must purchase the product through online channels. In other words, for consumers, $v=1, u_{i 1} \geq 0$ and $u_{i 1} \geq u_{i 2}$, $V=\eta / \delta, u_{i 2} \geq 0$ and $u_{i 2} \geq u_{i 1}$; therefore, $0<\eta<\delta<1$ can be obtained.

\section{The Establishment of a Dual-Channel Game Model and the Establishment of a New Retail Model}

3.1. Establishment and Comparison of Three Models in Dual Channels. In model 0 , there are only physical channels. In this case, consumers can only select and purchase products through physical channels, so the consumer's valuation is $v \geq p(v \in[p, 1]), u 0=v-p>0$, and the demand function is $q_{0}=1-p$.

In Model 1 and Model 2, when the consumer is [(1$\eta / 1-p) p, 1]$ estimated to be $1 \%$, consumers will buy products from physical channels; at this time $u_{i 1} \geq 0$, and $u_{i 2} \geq u_{i 1}$; consumers are estimated $[(\eta / \delta) p,(1-\eta / 1-\delta) P]$ to buy products from online channels; at this time, uil $\geq 0$ and uil $\geq$ ui2. Therefore, the effective demand of physical channels and network channels are, respectively, $q_{i 1}=1-(1-\eta / 1-\delta) p, q_{i 2}=((1-\eta / 1-\delta)-(\eta / \delta)) p$, and there is always demand in the supply chain as $q=q_{i 1}+q_{i 2}=p$ $1-(\eta / \delta) p$. 
3.1.1. Model 0. With manufacturer's wholesale price $w$ and retailer's retail price $p$, through reverse induction, the retailer's decision-making problem is given as

$$
\max _{0<p<1} \pi_{\mathrm{OR}}=q_{0}(p-w)=(1-p)(p-w) .
$$

The inverse function of the retailer from the first-order optimal condition is

$$
p_{0}^{*} p_{0}^{*}\left(\frac{1+w}{2}\right)
$$

Get the manufacturer:

$$
\max _{0<w<1} \pi_{\mathrm{OM}}=1-p_{0}^{*} w .
$$

According to the first-order optimal advantage conditions, the manufacturer's optimal wholesale price $w_{0}^{*}=1 / 2$.

3.1.2. Model 1. From the previously obtained $p$, and $p$, the manufacturer, as the leader of the Stackelberg game model, sets the wholesale price $w$, so the retailer's decision-making problem is

$$
\max _{p} \pi_{1 R=q_{11}}(p-w)=\left(1-\frac{1-\eta}{1-\delta}\right)(p-w) .
$$

According to the characteristics of the required function, the retailer's response function is optimally

$$
p_{1}^{*}=\frac{1}{2}\left(w+\frac{1-\delta}{1-\eta}\right) \text {. }
$$
is

Therefore, the manufacturer's decision-making problem

$$
\max _{w} \pi_{1 M=q_{11}} w+q_{12} \eta p_{1}^{*}=\left(1-\frac{1-\eta}{1-\delta} p_{1}^{*}\right) w+\left(\frac{1-\eta}{1-\delta}-\frac{\eta}{\delta}\right) \eta p_{1}^{* 2} .
$$

The manufacturer's decision-making problem is about giving the second concave of the wholesale price and obtaining the optimal wholesale price according to the existing conditions:

$$
w_{1}^{*}=\frac{(1-\delta)\left(\delta-\eta^{2}\right)}{(1-\eta)\left(\eta^{2}-3 \delta \eta+2 \delta\right)} .
$$

Then the reaction function is introduced to obtain the optimal retail price of the retailer's physical channel as

$$
p_{1}^{*}=\frac{1}{2}\left(\frac{3 \delta(1-\delta)}{\eta^{2}-3 \delta \eta+2 \delta}\right) .
$$

Bringing $w_{1}^{*}, p_{1}^{*}$ into can get the optimal demand of model 2.

3.1.3. Model 2. With the decision-making problem obtained from the previous $q_{21}=1-(1-\eta / 1-\delta) p$ and $t$ $q_{22}=((1-\eta / 1-\delta)-(\eta / \delta)) p$, the retailer is

$$
\begin{aligned}
\max _{p} \pi_{2 R}= & q_{21}(p-w)+q_{22}(\eta p-w)=\left(1-\frac{1-\eta}{1-\delta} p\right)(p-w) \\
& +\left(\frac{1-\eta}{1-\delta}\right)(\eta p-w) p .
\end{aligned}
$$

According to the first-order optimal condition of the concave shape of the given function, the response function of the retailer is obtained:

$$
p_{2}^{*}=\frac{1}{2}\left(\frac{1-\delta}{\eta^{2}-2 \delta \eta+\delta}\right)(\eta w+\delta) .
$$

According to the retailer's reaction function, the manufacturer's decision-making problem is

$$
\max _{w} \pi_{2 M}=\left(1-\frac{\delta}{\eta} p_{2}^{*}\right) w .
$$

The manufacturer's decision-making problem is about the second concave, and the optimal wholesale price can be obtained according to the first-order optimal condition:

$$
w_{2}^{*}=\frac{1}{2}\left(\frac{2 \delta^{2}-\delta \eta-3 \delta^{2} \eta+2 \delta^{2} \eta}{\eta^{2}(1-\delta)}\right) .
$$

By bringing into the reaction function, the optimal retail price of the retailer's physical channel can be obtained:

$$
p_{2}^{*}=\frac{\delta}{4 \eta}\left(\frac{2 \delta^{2}-5 \delta \eta+2 \delta+\eta}{\eta^{2}-2 \delta \eta+\delta}\right) .
$$

Appropriately bring $w_{2}^{*}, p_{2}^{*}$ into the expression that can obtain the optimal demand of model 2 , the most profitable, etc.

$$
\begin{aligned}
& A=\frac{1-\delta}{\eta^{2}-3 \delta \eta+2 \delta} \\
& B=\frac{2 \delta^{2}-(5 \delta-1) \eta+2 \delta}{\eta^{2}-2 \delta \eta+\delta} .
\end{aligned}
$$

The common feasible conditions of Model 1 and Model 2 are

$$
\begin{array}{ll}
0<w_{1}^{*}<\eta p_{1}^{*}, & p_{1}^{*}<\frac{1-\delta}{1-\eta}, \\
0<w_{2}^{*}<\eta p_{2}^{*}, & p_{2}^{*}<\frac{1-\delta}{1-\eta} .
\end{array}
$$

Get

$$
R=\left\{(\eta, \delta) \mid \frac{2}{3}<\eta<1, \eta<\delta<\min \left\{C_{0}(\eta), C_{0}(\eta), C_{0}(\eta)\right\}\right\} .
$$

In the region $R$, the profit of each channel of the models 1 and 2 is all positive [5]. 
3.2. Analysis of Online and Offline Models in the Context of New Retail.

(1) The influence of service level on the pricing of retail enterprises $\left(S_{r}, S_{R}\right)$.

Corollary 1. The optimal price of $P_{r}^{*}$ physical retail is positively correlated with its price level $S_{r}$, so when decentralizing decision-making [6], the entity-led Stackelberg game:

$$
\frac{\partial p_{r}^{*}}{\partial_{S}^{r}}=\frac{K_{5}+2 K_{7}}{2\left(2 \alpha_{1}^{2}-2 \alpha_{2}^{2}\right)}=\frac{2 \alpha_{1} \beta_{1}+\eta \theta\left(2 \alpha_{1}^{2}-2 \alpha_{2}^{2}\right)}{2\left(2 \alpha_{1}^{2}-\alpha_{2}^{2}\right)}>0 .
$$

Stackelberg game dominated by e-commerce:

$\frac{\partial P_{r}^{*}}{\partial S_{r}}=\frac{K_{12}=2 K_{14}^{*}}{2\left(2 \alpha_{1}^{2}-\alpha_{2}^{2}\right)}=\frac{4 \alpha_{1}^{2} \beta-\alpha_{2}^{2}-2 \alpha_{1} \alpha_{2 \beta_{2}}+\eta \theta \alpha_{1}\left(4 \alpha_{1}^{2}-\alpha_{2}^{2}\right)}{2\left(2 \alpha_{1}^{2}-\alpha_{2}^{2}\right)}>0$.

Nondominant Bertrand model:

$$
\frac{\partial P_{r}^{*}}{\partial S_{r}}=\frac{K_{5}^{\prime \prime}+2 K_{7}^{\prime \prime}}{4 \alpha_{1}^{2}-\alpha_{2}^{2}}=\frac{2 \alpha_{1} \beta_{1}-\alpha_{2} \beta_{2}+2 \eta \theta \alpha_{1}^{2}}{4 \alpha_{1}^{2}-\alpha_{2}^{2}}>0 .
$$

Game without dominance under centralized decisionmaking:

$$
\frac{\partial P_{R}^{*}}{\partial S_{R}^{*}}=\frac{K_{11}^{\prime \prime}+2 K_{13}^{\prime \prime}}{2\left(\alpha_{1}^{2}-\alpha_{2}^{2}\right)}=\frac{2 \alpha_{1} \beta_{1}-\alpha_{2} \beta_{2}+\eta\left(\alpha_{1}^{2}-\alpha_{2}^{2}\right)}{2\left(\alpha_{1}^{2}-\alpha_{2}^{2}\right)}>0 .
$$

Because $\quad \alpha_{1}>\alpha_{2}, \beta_{1}>\beta_{2} \quad 0<\eta<1,0<\theta<1, \quad$ so $\left(\partial P_{R}^{*} / \partial S_{R}\right)>0$, get proof.

Corollary 2. There is a positive correlation between $P_{r}^{*}$, the optimal retail price of e-commerce, and $S_{r}$, the retail price level of e-commerce [7].

When decentralizing decision-making, the entity-led Stackelberg game:

$$
\frac{\partial p_{r}^{*}}{\partial S_{r}}=\frac{K_{11}+2 K_{13}}{2\left(2 \alpha_{1}^{2}-2 \alpha_{2}^{2}\right)}=\frac{4 \alpha_{1}^{2} \beta_{1}-\alpha_{2}^{2} \beta_{1}-2 \alpha_{1} \alpha_{2} \beta_{2}+\eta \theta \alpha_{1}\left(4 \alpha_{1}^{2}-\alpha_{2}^{2}\right)}{4 \alpha_{1}\left(2 \alpha_{1}^{2}-\alpha_{2}^{2}\right)}>0 .
$$

Stackelberg game dominated by e-commerce:

$$
\frac{\partial P_{r}^{*}}{\partial S_{r}}=\frac{K_{4}^{\prime}+2 K_{6}^{\prime}}{2\left(2 \alpha_{1}^{2}-\alpha_{2}^{2}\right)}=\frac{2 \alpha_{1}^{2} \beta_{1}-\alpha_{2}^{2} \beta_{1}-2 \alpha_{1} \alpha_{2} \beta_{2}+\eta \theta\left(2 \alpha_{1}^{2}-\alpha_{2}^{2}\right)}{2\left(2 \alpha_{1}^{2}-\alpha_{2}^{2}\right)}>0 .
$$

Nondominant Bertrand model:

$$
\frac{\partial P_{R}^{*}}{\partial S_{R}}=\frac{K_{11}^{\prime \prime}+2 K_{13}^{\prime \prime}}{4 \alpha_{1}^{2}-\alpha_{2}^{2}}=\frac{2 \alpha_{1} \beta_{1}-\alpha_{2} \beta_{2}+2 \eta \theta \alpha_{1}^{2}}{4 \alpha_{1}^{2}-\alpha_{2}^{2}}>0 .
$$

Game without leading when centralizing decisionmaking:

$$
\frac{\partial P_{R}^{*}}{\partial S_{R}^{*}}=\frac{K_{11}^{\prime \prime}+2 K_{13}^{\prime \prime}}{2\left(\alpha_{1}^{2}-\alpha_{2}^{2}\right)}=\frac{\alpha_{1} \beta_{1}-\alpha_{2} \beta_{2}+\eta\left(\alpha_{1}^{2}-\alpha_{2}^{2}\right)}{2\left(\alpha_{1}^{2}-\alpha_{2}^{2}\right)}>0 .
$$

Because $\quad \alpha_{1}>\alpha_{2}, \beta_{1}>\beta_{2} \quad 0<\eta<1,0<\theta<1, \quad$ so $\left(\partial P_{R}^{*} / \partial S_{R}\right)>0$, get proof.

Corollary 3. The optimal retail price of e-commerce is $P_{R}^{*}$ positively correlated with the service level of logistics enterprises $S_{T R}[8]$.

When decentralizing decision-making, the entity-led Stackelberg game:

$$
\frac{\partial p_{R}^{*}}{\partial S_{\mathrm{TR}}}=\frac{K_{11}}{4\left(2 \alpha_{1}^{2}-\alpha_{2}^{2}\right)}=\frac{4 \alpha_{1}^{2} \beta_{1}-\alpha_{2}^{2} \beta_{1}+2 \alpha_{1} \alpha_{2} \beta_{2}}{4 \alpha_{1}\left(2 \alpha_{1}^{2}-\alpha_{2}^{2}\right)}>0 .
$$

Stackelberg game dominated by e-commerce:

$$
\frac{\partial p_{R}^{*}}{\partial S_{\mathrm{TR}}}=\frac{K_{4}^{\prime}}{4 \alpha_{1}\left(2 \alpha_{1}^{2}-\alpha_{2}^{2}\right)}=\frac{2 \alpha_{1} \beta_{1}-\alpha_{2} \beta_{1}}{4 \alpha_{1}\left(2 \alpha_{1}^{2}-\alpha_{2}^{2}\right)}>0 .
$$

Nondominant Bertrand model:

$$
\frac{\partial p_{R}^{*}}{\partial S_{\mathrm{TR}}}=\frac{K_{11}^{\prime}}{4 \alpha_{1}^{2}-\alpha_{2}^{2}}=\frac{2 \alpha_{1} \beta_{1}-\alpha_{2} \beta_{2}}{4 \alpha_{1}^{2}-\alpha_{2}^{2}}>0 .
$$

Game without leading when centralizing decisionmaking:

$$
\frac{\partial P_{R}^{*}}{\partial S_{\mathrm{TR}}^{*}}=\frac{K_{11}^{\prime \prime}}{2\left(\alpha_{1}^{2}-\alpha_{2}^{2}\right)}=\frac{\alpha_{1} \beta_{1}-\alpha_{2} \beta_{2}}{2\left(\alpha_{1}^{2}-\alpha_{2}^{2}\right)}>0 .
$$

Because $\quad \alpha_{1}>\alpha_{2}, \beta_{1}>\beta_{2} \quad 0<\eta<1,0<\theta<1, \quad$ so $\left(\partial P_{R}^{*} / \partial S_{R}\right)>0$, get proof.

Corollary 4. Under the decentralized decision-making, the physical retail optimal price is $P_{r}^{*}$ positively correlated with the logistics enterprise price $P_{T R}^{*}$.

Under centralized decision-making, there is no correlation between $P_{T R}^{*}$, the physical retail optimal price, and the logistics enterprise price, $P_{T R}$. The optimal retail price of e-commerce is $P_{R}^{*}$ negatively correlated with the service level of logistics enterprises $S_{T R}$.

When decentralizing decision-making, the entity-led Stackelberg game:

$$
\begin{aligned}
& \frac{\partial p_{r}^{*}}{\partial S_{\mathrm{TR}}}=\frac{K_{3}}{2\left(2 \alpha_{1}^{2}-\alpha_{2}^{2}\right)}=\frac{\alpha_{1} \alpha_{2}}{2\left(2 \alpha_{1}^{2}-\alpha_{2}^{2}\right)}>0, \\
& \frac{\partial p_{R}^{*}}{\partial S_{\mathrm{TR}}}=\frac{K_{10}}{4 \alpha_{1}\left(2 \alpha_{1}^{2}-\alpha_{2}^{2}\right)}=\frac{3 \alpha_{1} \alpha_{2}^{2}-4 \alpha_{1}^{3}}{4 \alpha_{1}\left(2 \alpha_{1}^{2}-\alpha_{2}^{2}\right)}>0 .
\end{aligned}
$$

Stackelberg game dominated by e-commerce:

$$
\begin{aligned}
& \frac{\partial p_{r}^{*}}{\partial S_{\mathrm{TR}}}=\frac{K_{10}^{\prime}}{4 \alpha_{1}\left(2 \alpha_{1}^{2}-\alpha_{2}^{2}\right)}=\frac{2 \alpha_{1}^{2} \alpha_{2}-\alpha_{2}^{3}}{4 \alpha_{1}\left(2 \alpha_{1}^{2}-\alpha_{2}^{2}\right)}>0, \\
& \frac{\partial p_{R}^{*}}{\partial S_{\mathrm{TR}}}=\frac{K_{3}^{\prime}}{2\left(2 \alpha_{1}^{2}-\alpha_{2}^{2}\right)}=\frac{\alpha_{2}^{2}-2 \alpha_{1}^{2}}{2\left(2 \alpha_{1}^{2}-\alpha_{2}^{2}\right)}>0 .
\end{aligned}
$$


Nondominant Bertrand model:

$$
\begin{gathered}
\frac{\partial p_{r}^{*}}{\partial S_{\mathrm{TR}}}=\frac{K_{3}^{\prime \prime}}{4 \alpha_{1}^{2}-\alpha_{2}^{2}}=\frac{\alpha_{1} \alpha_{2}}{4 \alpha_{1}^{2}-\alpha_{2}^{2}}>0, \\
\frac{\partial p_{R}^{*}}{\partial S_{\mathrm{TR}}}=\frac{K_{10}^{\prime \prime}}{4 \alpha_{1}^{2}-\alpha_{2}^{2}}=\frac{\alpha_{2}^{2}-2 \alpha_{1}^{2}}{4 \alpha_{1}^{2}-\alpha_{2}^{2}}>0 .
\end{gathered}
$$

Because $\alpha_{1}>\alpha_{2}\left(\partial P_{r}^{*} / \partial S_{R}\right)>0,\left(\partial P_{R}^{*} / \partial S_{R}\right)<0$ is proved.

\section{Model Evaluation}

4.1. Model Evaluation for the Introduction of Online Supply Channels. Taking the manufacturer's single channel and the retailer's overall profit as a comparison factor and comparing the manufacturer's and retailer's dual-channel and the overall profit of the supply chain, the following propositions are obtained [9].

Under the feasible region $R$, the three channel structures, the profit of each channel, and the overall profit of the supply chain satisfy the following relationship:

(1) Manufacturers' profit satisfaction under the three supply chain structure channels $\pi_{1 M}^{*}>\pi_{2 M}^{*}>\pi_{0 M}^{*}$.

(2) The profit of the retailer under the three supply chain channel structures is satisfied, when $(\eta, \delta) \in A$ $\pi_{2 R}^{*}<\pi_{1 R}^{*}<\pi_{0 R}^{*} \quad(\eta, \delta) \in B$, and retailer profits $\pi_{1 R}^{*}<\pi_{2 R}^{*}<\pi_{0 R}^{*}$.

(3) Under the three supply chain channel structures, the overall supply chain is satisfied $\pi_{1 D}^{*}>\pi_{0 D}^{*}>\pi_{2 D}^{*}$, proving

$$
\pi_{1 M}^{*}-\pi_{2 M}^{*}=\frac{(\delta-\eta) f(\eta, \delta)}{8 \eta^{2}(1-\delta)(1-\eta)\left(\eta^{2}-2 \delta \eta+\delta\right)\left(\eta^{2}-3 \delta \eta+2 \delta\right)}
$$

$$
f(\eta, \delta)=A \eta^{3}+B \delta^{2}+C \delta+D A=-39 \delta^{4}+83 \delta^{3}-88 \delta^{2}+
$$
$44 \delta-8, B=\left(25 \eta^{3}-22 \eta^{2}+30 \eta-12\right) \eta^{2}, C=\left(-4 \eta^{3}-8 \eta^{2}-\right.$ $19 \eta+7) \eta^{3}, \quad D=8 \eta^{5}$. For simple calculation $g(\eta, \delta)=$ $(\partial f / \partial \delta)=3 A \delta^{2}+2 B \delta+C, \Delta(\eta)=-2 B-\sqrt{4 B^{2}-12 A C} / 6 A$, due to $\eta \in((2 / 3), 1), g \quad(\eta, \eta)=-\eta^{2}\left(65 \eta^{2}-67 \eta+24\right)$ $\left(1-\eta^{2}\right)<0$, and

$$
g(\eta, 1)=\left(4 \eta^{3}-9 \eta^{2}+15 \eta-6\right)(1-\eta)^{3}>0, \quad \eta \in\left(\frac{2}{3}, 1\right),
$$$$
\delta<\eta<\Delta(\eta)
$$

In addition, it can be calculated that $C_{1}(\eta)<\Delta(\eta)$, $f(\eta, \eta)=\eta^{3}(15 \eta-8)(1-\eta)^{3}>0$, and

$$
f\left(\eta, C_{1}(\eta)\right)=\left(6 \eta ^ { 5 } ( 1 - \eta ) ^ { 3 } ( \eta - 2 ) \quad \left(12 \eta^{3}-32 \eta^{2}+29-\right.\right.
$$
10) $\left./\left(3 \eta^{2}-3 \eta+2\right)^{3}\right)>0$. So in the feasible region $f(\eta, \delta)>0$. So it is established that $\pi_{1 M}^{*}>\pi_{2 M}^{*}$, and then prove $\pi_{2 M}^{*}>\pi_{1 M}^{*}$,

$$
\begin{aligned}
\pi_{2 M}^{*}>\pi_{0 M}^{*} & \Leftrightarrow \frac{1}{8} \frac{\delta\left(2 \delta-\eta-3 \delta \eta+2 \eta^{2}\right)^{2}}{8 \eta^{2}(1-\eta)\left(\eta^{2}-2 \delta \eta+\delta\right)}>\frac{1}{8} \\
& \Leftrightarrow\left(9 \eta^{2}-12 \eta+4\right) \delta^{2}+\left(-5 \eta^{3}+3 \eta^{2}\right) \delta+\eta^{3}>0 .
\end{aligned}
$$

Order $\quad h(\eta, \delta)=\left(9 \eta^{2}-12 \eta+4\right) \delta^{2}+\left(-5 \eta^{2}+3 \eta^{2}\right)$ $\delta+\eta^{3}>0$, and then

$h(\eta, 1)=4(1-\eta)^{3}>0, \quad$ because $\quad \partial h / \partial \delta=2\left(9 \eta^{2}-\right.$ $12 \eta+4) \delta+\left(-5 \eta^{3}+3 \eta^{2}\right)=(1-\eta)\left(5 \eta^{2}-16 \eta+8\right)<0$, and we an get $\pi_{2 R}^{*}<\pi_{0 R}^{*}$, and then

$$
\pi_{1 R}^{*}<\pi_{2 R}^{*} \Leftrightarrow(\delta-\eta) f(\eta, \delta)>0 \Leftrightarrow f(\eta, \delta)>0 .
$$

Among them $f(\eta, \delta)=A \delta^{2}+B \delta+C$; among them $A=36 \eta^{2}-24 \eta^{2}+4 B=-21 \eta^{3}-23 \eta^{2}+12 \eta, C=\eta^{4}+15 \eta^{3}$. And $A>0$ and $\Delta>B^{2}-4 A C=9 \eta^{2}(11 \eta-4) \quad(3 \eta-4)$ $(\eta-1)^{2}<0$, so $\pi_{1 R}^{*}<\pi_{2 R}^{*}$.

Similarly, it can also prove

$$
\pi_{2 R}^{*}<\pi_{0 R}^{*} \Leftrightarrow \frac{(\delta-\eta) f(\delta, \eta)}{16 \eta^{2}(1-\delta)(1-\eta)\left(\eta^{2}-2 \delta \eta+\delta\right)\left(\eta^{2}-3 \delta \eta+2 \delta\right)^{2}} .
$$

Among them

$$
\begin{aligned}
f(\eta, \delta) & =\left(-279 \eta^{5}+891 \eta^{4}-1264 \eta^{3}+924 \eta^{2}-336 \eta+48\right) \delta^{4} \\
& =\left(315 \eta^{6}-721 \eta^{5}+846 \eta^{4}-472 \eta^{3}+96 \eta^{3}\right) \delta^{3} \\
& =\left(-112 \eta^{7}+126 \eta^{6}-2171 \eta^{5}+123 \eta^{4}-16 \eta^{3}\right) \delta^{2} \\
& =\left(12 \eta^{8}+8 \eta^{7}+75 \eta^{6}-31 \eta^{5}\right) \delta-16 \eta^{7} .
\end{aligned}
$$

Therefore $\pi_{1 R}^{*}>\pi_{2 R}^{*} \Leftrightarrow f(\eta, \delta)>0$, and you can also get by calculation

$$
\begin{gathered}
\pi_{1 D}^{*}>\pi_{0 D}^{*} \Leftrightarrow\left(\frac{3 \delta(1-\delta)\left(\delta-\eta^{2}\right)}{4\left(\eta^{2}-3 \delta \eta+2 \delta\right)^{2}}\right)>\frac{1}{16}+\frac{1}{8} \Leftrightarrow-(\delta-\eta)\left[4 \delta^{2}+\left(5 \eta^{2}-8 \eta\right) \delta-\eta^{3}\right]>0, \\
\pi_{2 D}^{*}>\pi_{0 D}^{*} \Leftrightarrow\left(5 \eta^{2}-12 \eta+4\right) \delta^{3}+\left(-6 \eta^{3}+19 \eta^{2}-4 \eta\right) \delta^{2}+\left(\eta^{4}-10 \eta^{3}\right) \delta+3 \eta^{4}>0 .
\end{gathered}
$$


It is easy to get $\left.(\partial f / \partial \delta)\right|_{(\eta, 0)}=\eta^{4}-10 \eta^{3}<0,\left.\right|_{(\eta, \eta)}=$ $4 \eta^{2}(\eta-1)^{2}>0$,

$$
\begin{aligned}
\left.\frac{\partial f}{\partial \delta}\right|_{\left(\eta, C_{1}(\eta)\right)} & =\frac{3 \eta^{3}(\eta-1)^{2}\left(3 \eta^{3}-54 \eta^{2}+76 \eta-24\right)}{\left(3 \eta^{2}-3 \eta+2\right)^{2}}>0, \\
\left.\frac{\partial f}{\partial \delta}\right|_{(\eta, 1)} & =(\eta-1)^{2}\left(\eta^{2}-20 \eta+12\right)<0 .
\end{aligned}
$$

This shows that whether manufacturers or retailers introduce online channels, their profits will increase for manufacturers. Therefore, as the leader of the game, manufacturers will introduce online channels. The indispensable advantage of retail channels in the market depends on what kind of preferential decision is used to stretch the profit front. But from the perspective of occupying the market, the introduction of online channels by retailers happens to be the most beneficial. In the area $\mathrm{B}$ shown by the retailer, the more preferable item is to introduce the network channel by itself, and in the area A, the manufacturer is still inclined to open the network channel. Going forward, whether manufacturers or retailers introduce online channels, retailers' marginal profits and demand for physical channels are reduced, so the profits of physical channels will decrease, especially after the introduction of online channels, through further observation. The loss suffered by physical channels is incomparable to the profits made by retailers introducing online channels; that is, the overall profit of the supply chain will be reduced; however, the profits brought by manufacturers introducing online channels are higher than the losses of physical channels, namely, supply. The overall profit of the chain will increase [10].

From this, it can be obtained that if you choose to introduce online channels under channel preference, you will get better profits when you choose online channels.

\subsection{Evaluation of the Impact of Related Variables in Different} Models on Pricing. Using centralized decision-making and decentralized decision-making to analyze the different competition structures established, in the existing research on the online and offline dual-channel supply chain, the object of the study is not only the e-commerce itself, but also the service level of logistics enterprises. E-commerce service level, logistics service, and pricing affect the changes in the optimal pricing of two different retail entities, as shown in Table 1.

Studies have shown that comparing the service levels of logistics companies under all competition structures will have a positive and relevant impact on e-commerce retail prices. However, when logistics companies' service levels are also positively correlated with physical retail prices, logistics companies' service levels have a positive impact on e-commerce retail prices. The impact will be greater than the impact of physical retail prices [11].

4.3. Numerical Simulation Analysis. Through the above rational analysis, according to the relevant literature and related numerical simulations, the influence of the service levels of the two retail companies and the service and price levels of the logistics companies on the optimal prices of physical and e-commerce retail under decentralized decision-making and centralized decision-making is analyzed according to relevant literature and related numerical simulations. The basic parameters of the optimal pricing model in the new retail dual-channel supply chain are shown in Table 2 .

The corresponding parameter values in Table 2 are calculated according to the sales and optimization formulas and are theoretical values obtained from the influence and correlation of different parameters on different prices.

Analyze the impact of physical retail service levels on retail prices, and through the formula model in the previous section and the above numerical parameters, the impact of physical retail services and levels on the optimal price of physical retail and e-commerce retail can be obtained, respectively, as shown in Table 3.

The best price of e-commerce sales can be obtained through the price level of e-commerce information. The formula is a model obtained by guiding the optimal price impact of physical retail and e-commerce retail through physical retail service and level.

Run the above 7 formulas in Matlab software to get Figure 1. When decentralizing decision-making:

(i) $Y 1$ is the best decision-making price of the entityled pricing in the Stackelberg game.

(ii) $Y 2$ is the best decision price for physical retail pricing led by e-commerce in the Stackelberg game.

(iii) $Y 3$ is the best decision-making price for physical retail pricing without dominant in the Bertrand game.

(iv) Y4 is the best decision price of e-commerce retail pricing dominated by entities in Stackelberg game.

(v) $Y 5$ is the best decision price of e-commerce retail pricing dominated by e-commerce in Stackelberg game.

(vi) Y6 is the best decision price of e-commerce retail pricing without dominance in Bertrand game.

(vii) $Y 7$ is the optimal price of e-commerce retail in the nondominant game.

(1) Macroscopic Analysis. In terms of model quantity: The optimal price of e-commerce retail under centralized decision-making is not affected by the physical retail service level. Overall trend: with the improvement of physical retail service level, the optimal pricing of the two retailers, the four game models of the entity-led Stackelberg game under decentralized decision-making, e-commerce-led Stackelberg game, nondominant Bertrand game, and game under centralized decision-making are all improving.

(2) Microanalysis. Retailer horizontal comparison: The physical retail service level has a more obvious promotion effect on the optimal price of the channel than the optimal price of the nonlocal channel. Make 
TABLE 1: The impact of related variables on prices in different game models.

\begin{tabular}{|c|c|c|c|c|c|c|c|c|}
\hline \multicolumn{5}{|c|}{ Decentralized decision-making } & \multicolumn{4}{|c|}{ Centralized decision } \\
\hline \multicolumn{5}{|c|}{ Stackelberg model } & \multicolumn{4}{|c|}{ Bertrand model } \\
\hline & \multicolumn{2}{|c|}{ Entity-led } & \multicolumn{2}{|c|}{$\begin{array}{l}\text { E-commerce } \\
\text { dominance }\end{array}$} & \multicolumn{4}{|c|}{ Nondominant } \\
\hline$P$ & $S_{r}, S_{R}$ & $S_{\mathrm{TR}}, P_{\mathrm{TR}}$ & $S_{r} S_{R}$ & $S_{\mathrm{TR}} P_{\mathrm{TR}}$ & $S_{r} S_{R}$ & $S_{\mathrm{TR}} P_{\mathrm{TR}}$ & $S_{r} S_{R}$ & $S_{\mathrm{TR}} P_{\mathrm{TR}}$ \\
\hline $\begin{array}{l}1_{r} \\
P_{R}\end{array}$ & $O \uparrow$ & $\uparrow \downarrow$ & $O \uparrow$ & $\uparrow \downarrow$ & $O \uparrow$ & $\uparrow 1$ & $O \uparrow$ & $\uparrow \downarrow$ \\
\hline$P_{r}-P_{R}$ & $><$ & $<>$ & $><$ & $<>$ & $><$ & $<>$ & $><$ & $<>$ \\
\hline
\end{tabular}

$\uparrow$ means positive correlation, $\downarrow$ means negative correlation, $O$ means unable to judge, and "-"means no effect. In Table 1, $P_{r}$ represents the retail price of ecommerce and $P_{R}$ represents the physical retail price. $P_{r}-P_{R}$ represents the difference between physical and online prices. $S_{r}$ represents the retail price level of e-commerce, $S_{\mathrm{TR}}$ represents the service level of logistics enterprises, and $P_{\mathrm{TR}}$ represents the price of logistics enterprises. Add “*” to indicate the optimal value.

TABLE 2: The basic parameter values of the optimal pricing model of the dual-channel supply chain.

\begin{tabular}{lcc}
\hline Basic parameters & Variable name & Parameter value \\
\hline$W$ & Wholesale price per unit & 98 \\
$C_{b}$ & The cost of big data technology & 3 \\
$P_{\mathrm{TR}}$ & Logistics company price & 7 \\
$\mathrm{~A}$ & Indicates the total market size of retail enterprise products & 600 \\
$S_{r} S_{R} S_{\mathrm{TR}}$ & The service level of physical retail, e-commerce retail, and logistics companies & $9,9,9$ \\
$\alpha_{1}$ & The elasticity coefficient of market demand to price & 5 \\
$\alpha_{2}$ & Cross elasticity coefficient of market demand to price & 3 \\
$\beta_{1}$ & The elasticity coefficient of market demand to service & 5 \\
$\beta_{2}$ & Cross elasticity coefficient of market demand to service & \\
$\lambda$ & Consumers' channel preference coefficient for physical retail & \\
$\eta$ & Service cost factor & 0.3 \\
$\theta$ & Cost optimization factor under big data technology & 0.8 \\
\hline
\end{tabular}

TABLE 3: The impact of physical retail service levels on retail prices.

\begin{tabular}{lcc}
\hline Retail entity game type & Physical retail & E-commerce retail \\
\hline Decentralized-entity-led Stackelberg game & $P_{r}^{*}=0.06 S_{r}^{2}+0.5 S_{r}+154.373$ & $P_{R}^{*}=0.18 S_{r}^{2}-0.135 S_{r}+161.415$ \\
Decentralization-Stackelberg game dominated by e-commerce & $P_{r}^{*}=0.062 S_{r}^{2}+0.179 S_{r}+153.978$ & $P_{R}^{*}=0.14 S_{r}^{2}-0.134 S_{r}+159.897$ \\
Decentralized-undominant Bertrand game & $P_{r}^{*}=0.062 S_{r}^{2}+0.458 S_{r}+153.031$ & $P_{R}^{*}=0.13 S_{r}^{2}-0.123 S_{r}+159.453$ \\
Game under centralized decision & $P_{r}^{*}=0.17 S_{r}^{2}+0.4 S_{r}$ & No \\
\hline
\end{tabular}

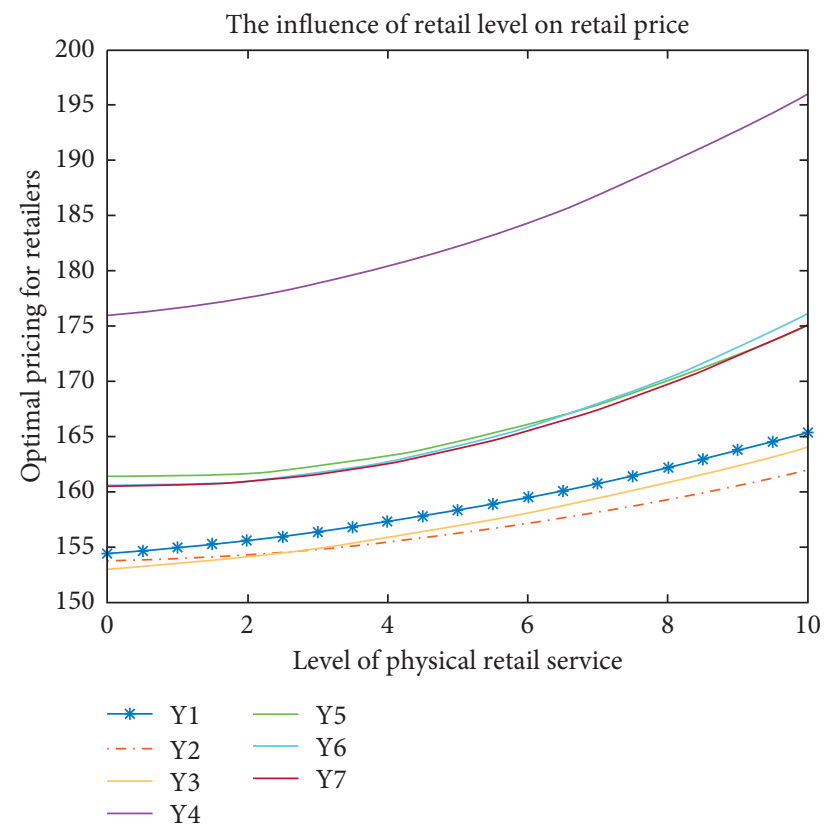

FIGURE 1: Changes in the impact of physical retail service levels on retail prices. 
TABLE 4: The effect of e-commerce retail service levels on the optimal price of physical retail and e-commerce retail.

\begin{tabular}{lcc}
\hline Retail entity game type & Physical retail & E-commerce retail \\
\hline Decentralized-entity-led Stackelberg game & $P_{r}^{*}=0.16 S_{r}^{2}-0.134 S_{r}+157.897$ & $P_{R}^{*}=0.067 S_{r}^{2}+0.487 S_{r}+155.415$ \\
Decentralization-Stackelberg game dominated by e-commerce & $P_{r}^{*}=0.016 S_{r}^{2}-0.131 S_{r}+159.213$ & $P_{R}^{*}=0.14 S_{r}^{2}-0.134 S_{r}+159.897$ \\
Decentralized-undominant Bertrand game & $P_{r}^{*}=0.016 S_{r}^{2}-0.123 S_{r}+159.976$ & $P_{R}^{*}=0.62 S_{r}^{2}+0.456 S_{r}+142.120$ \\
Game under centralized decision & No & $P_{r}^{*}=0.14 S_{r}^{2}+0.49 S_{r}+176.98$ \\
\hline
\end{tabular}

a vertical comparison of its different subjects in the competition structure: the centralized decisionmaking is superior to other several pricing models, and the promotion effect is the most obvious.

When centralizing decision-making:

The optimal decision price of physical retail pricing is in the y4 game.

The figure shows the following:

The impact of e-commerce retail service levels on retail prices: through the model formulas in the previous chapter and the parameter assumptions in the above table, the effect of e-commerce retail service levels on the optimal price of physical retail and e-commerce retail can be solved, respectively, as shown in Table 4.

Run the above 7 formulas in the Matlab software to get Figure 2, where we have the following.

When decentralizing decision-making:

$Y 1$ is the best decision price of the entity-led retail pricing in the Stackelberg game.

$Y 2$ is the best decision-making price for physical retail pricing led by e-commerce in the Stackelberg game.

$Y 3$ is the best decision-making price for physical retail pricing without leading in the Bertrand game.

Y4 is the best decision-making price of e-commerce retail pricing led by entities in the Stackelberg game.

$Y 5$ is the best decision price of e-commerce retail pricing in the Stackelberg game.

$Y 6$ is the best decision-making price for e-commerce retail pricing without leading in the Bertrand game.

When centralizing decision-making:

$Y 7$ is the e-commerce retail optimal price in the nondominant game.

The following can be seen from the figure: (1) Macroscopic analysis: $a$. The quantity of models: the optimal price of physical retail under centralized decision-making is not affected by the e-commerce retail service level. $b$. The overall trend: as the e-commerce retail service level increases, the e-commerce retail price, optimal pricing, is improved in four game models: the entity-led Stackelberg game under decentralized decision-making, the Stackelberg game led by e-commerce, the nondominant Bertrand game, and the game under centralized decision-making. (2) Microanalysis: a. Horizontal comparison of retailers: The optimal retail price of e-commerce and the service level of e-commerce are positively correlated, and the optimal price of physical retail and the e-commerce service level are first negatively

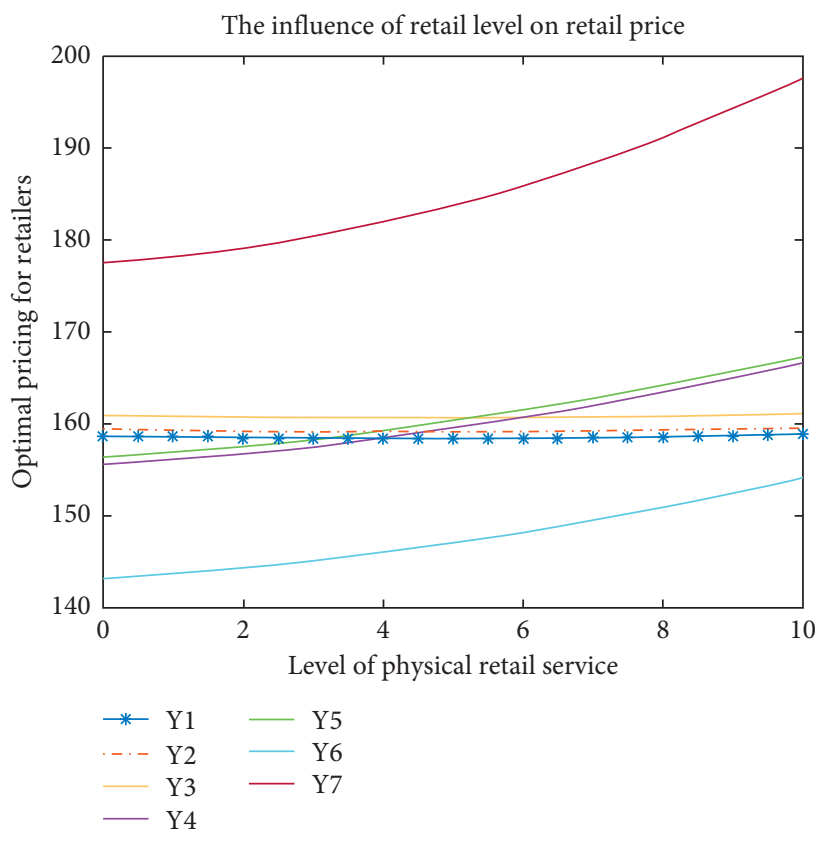

FIGURE 2: The impact of e-commerce retail service levels on retail price changes.

correlated and then positively correlated. At the same time, the e-commerce retail service level has a more obvious influence on the optimal price of this channel than the optimal price of the nonlocal channel. $b$. Vertical comparison of different competition structures: For the optimal pricing of e-commerce retail, the price under centralized decision-making is higher than the three game models under decentralized decision-making, and the promotion effect is the most obvious.

\section{Conclusion}

It can be seen that, in the context of new retail, the channel preference is mainly reflected in the introduction of network channels, which has a positive effect on the overall development of the supply chain and will increase the overall profit of the supply chain. The problem of supply chain pricing is unavoidable at any time. Even if the times are advancing and technology will continue to evolve, the relationship between the various factors in them is always interacting and influencing each other. Concentrating on solving the problems within the supply chain is the crux of the problem. Both online and offline channels should pay attention to their own service level. The improvement of service level will increase the profit to a certain extent. Therefore, for enterprises, it is necessary to not only improve 
the service level, but to pay attention to the integration of multiple factors [12]. Analyze and promote the long-term development of the enterprise. For choosing a logistics company, it should comprehensively evaluate its service level and price, so as to promote the increase of its own interests, meet the ever-evolving market demand, and increase the overall profit. The continuous progress of emerging technologies promotes the new retail business to a higher level. The development and application of big data technology by major groups and the rapid progress of Internet and Internet of Things technologies all promote the various entities in the new retail industry. The major groups and companies have joined forces and cooperated with each other, promoting the one-stop linkage service from product manufacturing to storage and maximizing the use of resources. Only in this way will it bring greater development space and more benefits to the enterprise.

\section{Data Availability}

The experimental data used to support the findings of this study are available from the corresponding author upon request.

\section{Conflicts of Interest}

The authors declare that they have no conflicts of interest regarding this work.

\section{References}

[1] T. Hendershott and J. Zhang, "A model of direct and Intermediated sales," Journal of Economics and Management Strategy, vol. 15, no. 2, pp. 279-316, 2006.

[2] S. Balasubramanian, "Mail versus Mall: a strategic analysis of competition between direct marketers and conventional retailers," Marketing Science, vol. 17, no. 3, pp. 181-195, 1998.

[3] H. Kurata, D.-Q. Yao, and J. J. Liu, "Pricing policies under direct vs. indirect channel competition and national vs. store brand competition," European Journal of Operational Research, vol. 180, no. 1, pp. 262-281, 2007.

[4] D. Grewal, R. Janakiraman, K. Kalyanam et al., "Strategic online and offline retail pricing: a review and research agenda," Journal of Interactive Marketing, vol. 24, no. 2, pp. 138-154, 2010.

[5] K. Cattani, W. Gilland, H. S. Heese et al., "Boiling Frogs: pricing strategies for a manufacturer adding a direct channel that competes with the traditional channel," Production and Operations Management, vol. 15, pp. 1-10, 2006.

[6] G. P. Cachon and M. A. Lariviere, ". Supply chain coordination with revenue-sharing contracts: strengths andLimitations," Management Science, vol. 51, no. 1, pp. 31-44, 2007.

[7] T. Boyaci, "Competitive stocking and coordination in a multiple-channel distribution system," IIE Transactions, vol. 37, no. 5, pp. 407-427, 2005.

[8] A. Enders and T. Jelassi, "The converging business models of Internet and bricks-and retailers," EuropeanManagement Jourmal, vol. 18, no. 5, pp. 542-550, 2000.

[9] W. Y. K. Chiang, "Product availability in competitive and cooperative dual-channel distribution withstock-out based substitution [J]," European Journal of Operational Research, vol. 200, no. 1, pp. 111-126, 2008.

[10] K.-Y. Chen, M. Kaya, and Ö. Özer, "Dual sales channel management with service competition," Manufacturing \& Service Operations Management, vol. 10, no. 4, pp. 654-675, 2008.

[11] B. Pietro, "Cooperation among prominent actors in a tourist destination," Annals of Tourism Research, vol. 8, no. 2, pp. 607-629, 2011.

[12] S. Y. Park and H. T. Keh, "Modelling hybrid distribution channels: a game-theoretic analysis," Journal of Retailing and Consumer Services, vol. 10, no. 3, pp. 155-167, 2003. 